\title{
Outcome of Endovascular Therapy Aiming for Single-session Obliteration of Intracranial Dural Arteriovenous Fistulas
}

\author{
Taichi IshIGURO, ${ }^{1}$ Tetsu SATOW,${ }^{1}$ Eika HAMANO,${ }^{1}$ Go IKEDA,${ }^{1}$ Hidekazu CHIKUIE, ${ }^{1}$ \\ Naoki Hashimura, ${ }^{1}$ Masaki Nishimura, ${ }^{1}$ Jun C. TAKAHASHI, ${ }^{1}$ \\ and Hiroharu KATAOKA ${ }^{1}$
}

${ }^{1}$ Department of Neurosurgery, National Cerebral and Cardiovascular Center, Suita, Osaka, Japan

\begin{abstract}
The goal of dural arteriovenous fistula (dAVF) treatment is obliteration of the arteriovenous shunt and/or retrograde leptomeningeal venous drainage (RLVD). Single-session obliteration could improve symptoms early and reduce risk of neurological sequelae. This study investigated the efficacy and adverse events of endovascular therapy (EVT) aiming for single-session obliteration in dAVF treatment. We retrospectively examined post-treatment arteriovenous shunt status, number of treatments per case, treatment-related complications, and long-term outcome in 92 dAVF patients who underwent initial EVT at our institution. Single-session obliteration was intended in all cases, but a second session was performed in cases of partial shunt occlusion or remaining RLVD. Complete occlusion was achieved in 85 cases $(92.4 \%)$ after the single session; RLVD was obliterated in 66 of the 67 Borden type II and III cases combined (98.5\%). A second session was necessary in seven cases ( $7.6 \%)$. Complete shunt obliteration was eventually achieved in all cases. The average number of treatments was 1.08 per case. dAVF-related stroke and mortality did not occur after the treatment. On the other hand, radiation-induced skin erythema and alopecia, although all symptoms were transient, occurred in 26 cases $(28.3 \%)$. Over an average 60.2-month follow-up period, recurrence was observed in seven cases (7.6\%). Single-session obliteration was successful in $92 \%$ of cases. Especially, single-session obliteration of RLVD may contribute to early prevent of future stroke events. However, reducing total radiation dose during each session is an issue of further study.
\end{abstract}

Keywords: dural arteriovenous fistula, embolization, endovascular, radiation, session

\section{Introduction}

Dural arteriovenous fistulas (dAVF) are characterized by abnormal arteriovenous shunts in the dura mater. Those with retrograde leptomeningeal venous drainage (RLVD) are associated with high rates of intracranial hemorrhage and cerebral infarction and require therapeutic intervention., ${ }^{1,2)}$ Endovascular therapy (EVT) is the preferred treatment option in many cases, particularly those draining into the cavernous sinus (CS) and transverse-sigmoid sinus (TS). ${ }^{3)}$

Received March 5, 2021; Accepted May 6, 2021

Copyright $@ 2021$ The Japan Neurosurgical Society This work is licensed under a Creative Commons AttributionNonCommercial-NoDerivatives International License.
However, multiple feeding arteries and shunt points are frequently involved, and procedures in multiple sessions on multiple days may be required for complete shunt obliteration.

In order to avoid the risk of intracranial complications and reduce the economic cost, we perform EVT that focuses on maximal obliteration of shunt in a single session. Herein, we report the outcomes of this approach and examine its advantages and disadvantages.

\section{Materials and Methods}

Study cohort

Ninety-five patients with intracranial dAVF who underwent EVT in our department between April 
2005 and December 2017 were identified. Three patients with residual or recurrent lesion after IVR at other institutions were excluded. A total of 92 dAVF patients who underwent initial EVT in our department were retrospectively examined in this study. The following data was analyzed: post-treatment shunt status, number of treatment sessions per case, treatment complications, recurrence, and adverse events. For patients with Borden type I dAVF, ${ }^{4)}$ treatment was initiated when patients presented with symptoms that disrupted activities of daily living (ADL) such as unbearable tinnitus causing insomnia, ocular movement disorders, or ocular hyperemia/protrusion. Treatment included transarterial embolization (TAE) alone, transvenous embolization (TVE) alone, or a combination of both. Patients with Borden type I were treated mainly with TAE to resolve their symptoms while preserving normal venous perfusion, and Borden type II were treated mainly with TVE for obliteration of RLVD. Single session obliteration was intended in all patients regardless of the number of shunt points. All procedures were performed under general anesthesia. N-butyl-cyanoacrylate (NBCA) was the liquid embolic agent used in all patients.

\section{Outcomes}

Angiographic shunt condition just after treatment was classified as follows: class 1, complete occlusion; class 2, slight shunt remnant; class 3a, remarkable shunt remnant (partial occlusion); and class 3b, RLVD remnant on digital subtraction angiography (DSA) (Fig. 1). The shunt condition was reevaluated at 7 days after the single session by angiography and for class $3 \mathrm{a}$ and $\mathrm{b}$ cases, a second session was performed at a later date. The operation time and the cumulative radiation dose absorbed per patient (reference air kerma) during each session were recorded using the DSA system. ${ }^{5)}$ The operation time was defined from the first manipulation of the surgeon until the last manipulation (e.g., from sheath insertion to sheath removal). Immediate morbidity, surgical complications, and postoperative outcomes were evaluated by neurosurgeons during the perioperative period. All patients received DSA at 6 months after treatment to assess recurrence, and then annual MRI follow-up.

\section{Results}

Patient characteristics, dAVF location, and Borden classification $^{4)}$ are summarized in Table 1. Average patient age was $63.5 \pm 10.9$ years and $52.2 \%$ of patients were male. Approximately $80 \%$ of the dAVF were located at the TS and CS $(43.5 \%$ and $33.7 \%$,

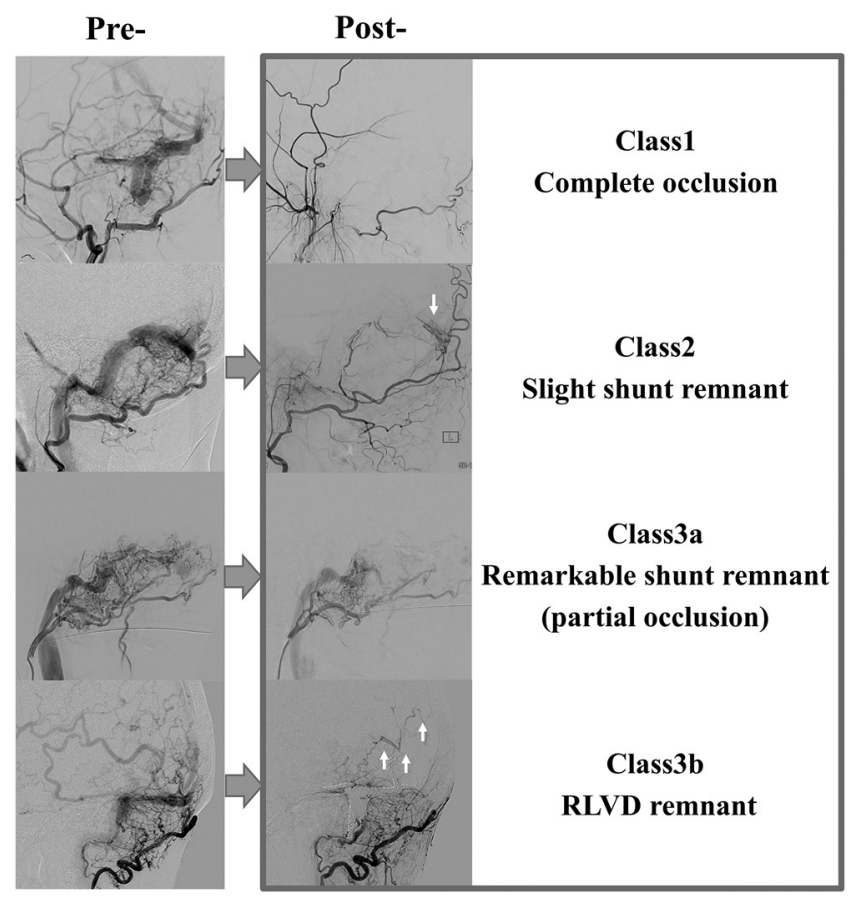

Fig. 1 Pre- and post-treatment (just after single-session) digital subtraction angiography (DSA) showing classification of treatment outcome: class 1, complete occlusion, class 2, slight shunt remnant (arrow), class 3a, remarkable shunt remnant (partial occlusion), and class $3 \mathrm{~b}$, retrograde leptomeningeal venous drainage (RLVD) remnant (arrows) on post-treatment DSA.

respectively). Distribution of Borden classification types was as follows: type I, $27.2 \%$; type II, $41.3 \%$; and type III, $31.5 \%$. Twenty cases $(21.7 \%)$ were treated by TAE alone, 41 cases $(44.6 \%)$ by TVE alone, and 31 cases $(33.7 \%)$ by combination TAE and TVE.

The number of cases with class $1,2,3 a$, and $3 \mathrm{~b}$ shunt status after initial treatment was $45,40,6$, and 1, respectively (Table 2). Eighty-five (92.4\%) were categorized as class 1 or 2 just after a single session; besides, slight shunt flow of class 2 cases was spontaneously obliterated by follow-up angiography. A second session was performed in the seven class $3 \mathrm{a}$ or $3 \mathrm{~b}$ cases. Eventually, complete shunt obliteration was achieved in all cases at 6 months after treatment. The total operation time per session was median 402 minutes (between 147 and $1093 \mathrm{~min}$, interquartile range 254-553 min). The total air kerma per session was median 6800 mGy (between 2000 and $38000 \mathrm{mGy}$, interquartile range 4400-11675 mGy).

Table 2 also shows the initial treatment outcome according to Borden classification. Class 3a outcome was achieved in four type I cases, one type II case, and one type III case; all six had multiple shunt 
Table 1 Patient and dAVF characteristics $(n=92)$

\begin{tabular}{lcc}
\hline Mean age (years) & $63.5 \pm 10.9$ & \\
Male & 48 & $52.2 \%$ \\
Hemorrhagic onset & 11 & $12.0 \%$ \\
Location & & \\
TS & 40 & $43.5 \%$ \\
CS & 31 & $33.7 \%$ \\
Tentorial & 7 & $7.6 \%$ \\
ACC & 6 & $6.5 \%$ \\
SSS & 3 & $3.3 \%$ \\
Other & 5 & $5.4 \%$ \\
Borden classification & & \\
Type I & 25 & $27.2 \%$ \\
Type II & 38 & $41.3 \%$ \\
Type III & 29 & $31.5 \%$ \\
Treatment procedure & & \\
TAE alone & 20 & $21.7 \%$ \\
TVE alone & 41 & $44.6 \%$ \\
Both TAE and TVE & 31 & $33.7 \%$ \\
\hline
\end{tabular}

ACC: anterior condylar confluence, CS: cavernous sinus, dAVF: dural arteriovenous fistula, SSS: superior sagittal sinus, TAE: transarterial embolization, TS: transverse-sigmoid sinus, TVE: transvenous embolization.

Table 2 Initial treatment outcome according to Borden classification

\begin{tabular}{lcccc}
\hline & \multicolumn{4}{c}{ Borden classification } \\
\cline { 2 - 5 } & Type I & Type II & Type III & Total \\
\hline $\begin{array}{l}\text { Treatment outcome } \\
\text { Class 1 }\end{array}$ & 9 & 23 & 13 & 45 \\
$\begin{array}{l}\text { Complete } \\
\text { occlusion }\end{array}$ & & & & \\
$\begin{array}{l}\text { Class 2 } \\
\text { Slight shunt } \\
\text { remnant }\end{array}$ & 12 & 13 & 15 & 40 \\
$\begin{array}{l}\text { Class 3a } \\
\text { Partial } \\
\text { occlusion }\end{array}$ & 4 & 1 & & \\
$\begin{array}{l}\text { Class 3b } \\
\text { RLVD } \\
\text { remnant }\end{array}$ & 0 & 1 & 0 & 6 \\
Total & 25 & 38 & 29 & 92 \\
\hline
\end{tabular}

RLVD: retrograde leptomeningeal venous drainage.

points. Among the type II cases, one had a class 3b outcome; this patient could not tolerate prolonged general anesthesia due to underlying diseases. RLVD
Table 3 Complications and long-term outcomes

\begin{tabular}{lcc}
\hline Treatment complications $(\mathrm{n}=92)$ & & \\
Skin erythema and alopecia & 26 & $28.3 \%$ \\
Occipital decubitus ulcer & 2 & $2.2 \%$ \\
Cranial nerve palsy & 5 & $5.4 \%$ \\
Femoral nerve palsy & 1 & $1.1 \%$ \\
Procedure-related intracranial & 2 & $2.2 \%$ \\
hemorrhage & 2 & $2.2 \%$ \\
Deterioration of mRS & 2 \\
Long-term outcome (n = 92) (mean follow-up, 60.2 \\
months) & \\
No deterioration & 82 & $89.1 \%$ \\
Recurrence & 7 & $7.6 \%$ \\
Sinus stenosis & 2 & $2.2 \%$ \\
Hydrocephalus & 1 & $1.1 \%$ \\
dAVF-related stroke & 0 & 0 \\
Mortality & 0 & 0 \\
\hline dAVF: dural arteriovenous fistula, mRS: modified Rankin \\
scale.
\end{tabular}

was obliterated by a single treatment in 66 of the $67(98.5 \%)$ type II and III cases combined.

Treatment complications included the following: skin erythema and alopecia in 26 cases $(28.3 \%)$, which were considered radiation-induced; occipital decubitus ulcer in two cases $(2.2 \%)$, which was likely caused by long-time compression; new or worsened cranial nerve palsy in five cases (5.4\%); and femoral nerve palsy due to puncture-related hematoma in one case $(1.1 \%)$ (Table 3 ). These complications were transient and subsequently improved. In addition, procedure-related intracranial hemorrhage occurred in two cases $(2.2 \%)$ that developed neurologic sequelae and deterioration of modified Rankin scale (mRS) score prior to discharge. Subarachnoid hemorrhage due to vessel perforation occurred in one patient, and acute subdural hematoma of unknown cause occurred in another; both of which were not considered to be owing to the strategy of single-session treatment itself.

Figure 2 illustrates a scatter plot of total operation time, air kerma, and presence/absence of skin disorder. The operation time and radiation dose showed a positive correlation (Pearson correlation coefficient was 0.875 ). The patients who suffered skin disorders had significantly longer operation time ( $\mathrm{p}<0.001)$ and higher air kerma ( $\mathrm{p}<0.001)$ compared with those without skin disorders. Fortunately, the skin erythema disappeared within 1-2 months, and the alopecia improved in 3-7 months (average 6 months) in all patients. 


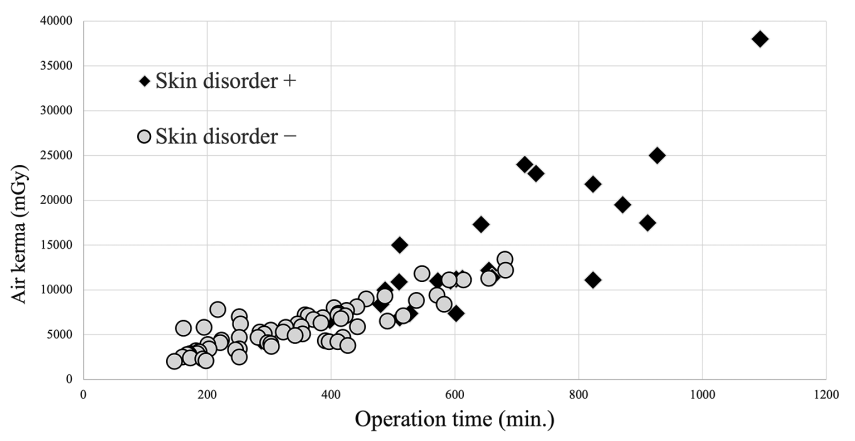

Fig. 2 A scatter plot showing all patient's operation time (minute), air kerma (mGy), and presence (black)/ absence (gray) of their skin disorder. The operation time and radiation dose showed a positive correlation (Pearson correlation coefficient was 0.875 ). The patients who suffered skin disorders had significantly longer operation time $(p<0.001)$ and higher air kerma $(p<0.001)$ compared with those without skin disorders.

Long-term outcome is also summarized in Table 3. Over an average 60.2-month follow-up period, shunt recurrence requiring retreatment occurred in seven cases $(7.6 \%)$. Progression of sinus stenosis that required percutaneous angioplasty to maintain normal venous outflow occurred in two cases $(2.2 \%)$. Progressive hydrocephalus requiring ventriculoperitoneal shunting developed in one of the patients who experienced procedure-related intracranial hemorrhage $(1.1 \%)$. There was no dAVF-related stroke or mortality during the follow-up period.

\section{Discussion}

The presence of direct arteriovenous shunting through the abnormal dural vascular connections that characterize dAVF can cause ocular symptoms, tinnitus, and cranial nerve palsy, depending on the site of shunting and route of venous drainage. ${ }^{1)}$ Approximately $1.5 \%-20 \%$ of dAVF with RLVD develop intracranial hemorrhage or cerebral infarction and require therapeutic intervention to prevent stroke. ${ }^{6,7)}$ EVT for dAVF is aimed at complete obliteration of the shunt and/or RLVD by TAE, TVE, or a combination of both. ${ }^{3,8)}$ However, as numerous feeding arteries and shunt points are often involved, treatment may need to be performed in multiple sessions on different days to avoid a prolonged single treatment.

In this study, $92 \%$ of cases resulted in complete obliteration or slight shunt remnant just after a single treatment session. In the slight shunt remnant cases, spontaneous obliteration which may be due to progressed thrombosis by nullifying heparinization after EVT was confirmed by follow-up angiography. RLVD obliteration was achieved after a single session in $99 \%$ of the Borden type II and III cases combined. Few previous reports mention the number of dAVF treatment sessions performed; the main ones are summarized in Table $4 .^{9-13)}$ In a report by Kuwayama et al., the average number of sessions per case was $1.83 .{ }^{11)}$ In studies that used ethylene vinyl alcohol copolymer (Onyx, Medtronic, Irvine, CA, USA) as the embolic agent, the average number was lower, approximately 1.3 per case. ${ }^{10,12)}$ However, in this study, the average number of sessions per case was even lower (1.08).

As to the technical aspects to achieve singlesession treatment, TVE was preferentially chosen in our series, up to $78.3 \%$. For instance, TVE focusing extirpation of RLVD were performed in all of Borden type 2 and 3 TSdAVFs. Also, TVE was frequently used while paying attention to preserving normal venous drainage in Borden type 1 TSdAVFs in order to eliminate the shunts as there were many tiny feeders which were difficult to embolize without Onyx, which had not been reimbursed at the study period. On the other hand, for CSdAVFs which should be treated by TVE, bilateral internal jugular vein approach was chosen so that we could reach and embolize the shunt points efficiently. When planning a single curative treatment, TVE enables the direct interruption of abnormal drainage even in cases having multiple feeders. However, sinus packing or mere occlusion of dangerous drainage is not recommended. Superselective shunt occlusion is feasible, effective, and can preserve normal venous perfusion, ${ }^{14)}$ which is our preferred technique. A procedure that introduces a microcatheter to the shunt point offers major advantages: it allows for

Table 4 The number of treatment sessions per case in previous reports and the present study

\begin{tabular}{lcccc}
\hline & $\begin{array}{c}\text { Total } \\
\text { case } \\
\text { (n) }\end{array}$ & $\begin{array}{c}\text { Total } \\
\text { session } \\
\text { (n) }\end{array}$ & $\begin{array}{c}\text { Average } \\
\text { number of } \\
\text { sessions } \\
\text { per case }\end{array}$ & Comment \\
\hline $\begin{array}{l}\text { Kuwayama } \\
\text { et al. }{ }^{11)}\end{array}$ & 105 & 192 & 1.83 & \\
$\begin{array}{l}\text { Cognard } \\
\text { et al. }{ }^{10)}\end{array}$ & 30 & 35 & 1.17 & Used \\
$\begin{array}{l}\text { Baltsavias and } \\
\text { Valavanis }\end{array}$ & 170 & 209 & 1.23 & ONYX \\
$\begin{array}{l}\text { Rangel-Castilla } \\
\text { et al. }{ }^{12)}\end{array}$ & 63 & 72 & 1.14 & Used \\
$\begin{array}{l}\text { Zogopoulos } \\
\text { et al. }{ }^{13)}\end{array}$ & 32 & 40 & 1.25 & ONYX \\
\begin{tabular}{l} 
Present study \\
\hline
\end{tabular} & 92 & 99 & 1.08 & \\
\hline
\end{tabular}


selective shunt occlusion with a small number of coils and avoids the risks of sinus packing, such as cranial nerve palsy. ${ }^{14-16)}$

Moreover, recurrence occurred in $7.6 \%$ of our cases during the follow-up period (average, 60.2 months), which is favorable compared to previous long-term studies that have reported long-term dAVF recurrence rates ranging from $9.5 \%$ to $21 \% .^{9,13,17)}$

\section{The efficacy and adverse events of obliteration in a single session}

The purpose of single session curative treatment is total obliteration of the shunt and/or RLVD. When obliteration is incomplete after the initial session, the RLVD remains and symptoms often deteriorate. ${ }^{9)}$ Van Dijk et al. reported an annual mortality rate of $10 \%$ in Borden type II and III dAVF with remnant RLVD; the incidence of adverse events such as stroke was $15 \%$ per year, ${ }^{7)}$ which is remarkably higher than the annual rupture rate of unruptured cerebral aneurysms and cerebral arteriovenous malformations. ${ }^{18,19)}$ We believe that the single-session approach is advantageous to eliminate the period of incomplete shunt or RLVD obliteration in Borden type II and III cases.

In contrast, the probability of Borden type I cases developing RLVD, or converting to type II or III, is as low as $1 \%-4 \%$ per year; the primary aim of treatment in type I cases is to improve clinical symptoms. ${ }^{6,20,21)}$ However, symptoms tend to remain if obliteration is incomplete and further treatment may be difficult due to changes in hemodynamics. ${ }^{21)}$ We believe that reducing these risks is an advantage of single-session treatment. Other advantages include: (1) single arterial puncture; (2) reduced physical and psychological burden on patients (less worry about risks of further procedures, incomplete dAVF treatment); and (3) reduced economic cost.

Nonetheless, characteristic adverse events were observed during this study: $28.3 \%$ incidence of radiation-induced skin erythema and alopecia due to the accumulated radiation dose during the procedure. According to a previous report, such skin disorder occurred in 19 cases (5.9\%) after 325 cases of EVT, especially the total radiation dose exceeded 5 Gy in $36 \%$ of the cases. ${ }^{22)}$ Since in most of our cases total air kerma exceeded $5 \mathrm{~Gy}$, our results were generally equivalent to those reported by the literature. Although these complications were transient, improved over time, and did not affect ADL, these problems cannot be ignored. When planning single-session treatment, it is essential to reduce the total and exposure radiation doses as much as possible by decreasing the irradiation field, pulse rate, and frame rate. ${ }^{23,24)}$ Furthermore, although no long-term adverse events, such as radiation-induced head and neck cancer, have yet occurred in this study, continuous monitoring will be required. For further issues, in radiosurgery, dividing an equivalent total radiation dose into several smaller fractions is less likely to cause radiation injury than a single large dose. ${ }^{25}$ However, it is unclear if this applies to EVT-related radiation exposure and there is no definite consensus as to how long the treatment interval should be. Additional research is needed to further clarify the advantages and disadvantages of single-session treatment.

Another concern is that prolonged procedure time may exhaust the interventionist's concentration, thus this method may be very useful when there is a well-disciplined team composed of several experienced neuroendovascular physicians.

\section{Limitations and further tasks}

Our study has several limitations. First, it is a single-center retrospective study. Second, since single-session EVT is the first-line treatment option at our center, it is difficult to directly compare our outcomes with those of different treatment methods.

Since Onyx (Medtronic), Squid (Emboflu, Galnd, Switzerland), or PHIL (MicroVention, Tustin, CA, USA) were not available in our country during the study era, NBCA was the only liquid embolic agent used in this study. Previous studies have shown that embolization using Onyx resulted in a significantly higher obliteration rate than NBCA and the recanalization rates were comparable. ${ }^{26,27)}$ Although radiation exposure was a major issue in this study, it is highly expected that effective use of other liquid embolic agents will reduce treatment time and radiation exposure. In Japan, the use of Onyx for treating dAVF has been reimbursed in 2018. Future outcome of single session treatment using Onyx is warranted.

\section{Conclusions}

Single-session EVT for dAVF treatment was successful in $92 \%$ of cases in this study. RLVD was obliterated in $99 \%$ of Borden type II and III cases combined, which may contribute to early prevention of future stroke events. However, when performing singlesession treatment, total radiation dose should be minimized to reduce transient radiation-induced complications including alopecia and skin erythema.

\section{Ethical Approval}

All procedures performed in this study were conducted in accordance with the ethical standards 
of the institutional and/or national research committee and the Declaration of Helsinki and its later amendments. This retrospective study was approved by the Ethics Committee of the institute and by the Ethics Committee of the National Cerebral and Cardiovascular Center (M30-013).

\section{Informed Consent}

Formal consent was not required for this study due to its retrospective observational nature.

\section{Conflicts of Interest Disclosure}

TS was supported by grants from CANON MEDICAL SYSTEMS CORPORATION, outside the submitted work. The authors declare that they have no conflict of interest.

\section{References}

1) Cognard C, Gobin YP, Pierot L, et al.: Cerebral dural arteriovenous fistulas: clinical and angiographic correlation with a revised classification of venous drainage. Radiology 194: 671-680, 1995

2) Davies MA, Ter Brugge K, Willinsky R, Wallace MC: The natural history and management of intracranial dural arteriovenous fistulae. Part 2: aggressive lesions. Interv Neuroradiol 3: 303-311, 1997

3) Lucas CP, Zabramski JM, Spetzler RF, Jacobowitz R: Treatment for intracranial dural arteriovenous malformations: a meta-analysis from the English language literature. Neurosurgery 40: 1119-1130; discussion 1130-1132, 1997

4) Borden JA, Wu JK, Shucart WA: A proposed classification for spinal and cranial dural arteriovenous fistulous malformations and implications for treatment. J Neurosurg 82: 166-179, 1995

5) Moritake T, Matsumaru Y, Takigawa T, Nishizawa K, Matsumura A, Tsuboi K: Dose measurement on both patients and operators during neurointerventional procedures using photoluminescence glass dosimeters. AJNR Am J Neuroradiol 29: 1910-1917, 2008

6) Gross BA, Du R: The natural history of cerebral dural arteriovenous fistulae. Neurosurgery 71: 594-602; discussion 602-603, 2012

7) van Dijk JM, terBrugge KG, Willinsky RA, Wallace MC: Clinical course of cranial dural arteriovenous fistulas with long-term persistent cortical venous reflux. Stroke 33: 1233-1236, 2002

8) Kiyosue H, Hori Y, Okahara M, et al.: Treatment of intracranial dural arteriovenous fistulas: current strategies based on location and hemodynamics, and alternative techniques of transcatheter embolization. Radiographics 24: 1637-1653, 2004

9) Baltsavias G, Valavanis A: Endovascular treatment of 170 consecutive cranial dural arteriovenous fistulae: results and complications. Neurosurg Rev 37: 63-71, 2014

10) Cognard C, Januel AC, Silva NA, Tall P: Endovascular treatment of intracranial dural arteriovenous fistulas with cortical venous drainage: new management using Onyx. AJNR Am J Neuroradiol 29: 235-241, 2008

11) Kuwayama N, Kubo M, Hori E, Tsumura K, Eiraku N, Endo S: Dural arteriovenous fistulas: complications of endovascular treatment. Surg Cereb Stroke 34: 91-95, 2006 (Japanese)

12) Rangel-Castilla L, Barber SM, Klucznik R, Diaz O: Mid and long term outcomes of dural arteriovenous fistula endovascular management with Onyx. Experience of a single tertiary center. J Neurointerv Surg 6: 607-613, 2014

13) Zogopoulos P, Nakamura H, Ozaki T, et al.: Endovascular treatment of intracranial dural arteriovenous fistulas-clinical and radiographic outcome over a longterm follow-up. Open Access J Neurol Neurosurg 1: 555553, 2015

14) Satow T, Murao K, Matsushige T, Fukuda K, Miyamoto S, Iihara K: Superselective shunt occlusion for the treatment of cavernous sinus dural arteriovenous fistulae. Neurosurgery 73: 100-105, 2013

15) Bink A, Goller K, Lüchtenberg M, et al.: Long-term outcome after coil embolization of cavernous sinus arteriovenous fistulas. AJNR Am J Neuroradiol 31: 1216-1221, 2010

16) Nishino $K$, Ito $Y$, Hasegawa $H$, et al.: Cranial nerve palsy following transvenous embolization for a cavernous sinus dural arteriovenous fistula: association with the volume and location of detachable coils. $J$ Neurosurg 109: 208-214, 2008

17) Ambekar S, Gaynor BG, Peterson EC, Elhammady MS: Long-term angiographic results of endovascularly "cured" intracranial dural arteriovenous fistulas. $J$ Neurosurg 124: 1123-1127, 2016

18) Greving JP, Wermer MJ, Brown RD, et al.: Development of the PHASES score for prediction of risk of rupture of intracranial aneurysms: a pooled analysis of six prospective cohort studies. Lancet Neurol 13: 59-66, 2014

19) Mohr JP, Parides MK, Stapf C, et al.: Medical management with or without interventional therapy for unruptured brain arteriovenous malformations (ARUBA): a multicentre, non-blinded, randomised trial. Lancet 383: 614-621, 2014

20) Kim DJ, terBrugge K, Krings T, Willinsky R, Wallace $\mathrm{C}$ : Spontaneous angiographic conversion of intracranial dural arteriovenous shunt: long-term follow-up in nontreated patients. Stroke 41: 1489-1494, 2010

21) Shah MN, Botros JA, Pilgram TK, et al.: BordenShucart Type I dural arteriovenous fistulas: clinical course including risk of conversion to higher-grade fistulas. J Neurosurg 117: 539-545, 2012

22) Kirkwood ML, Arbique GM, Guild JB, Timaran C, Valentine RJ, Anderson JA: Radiation-induced skin injury after complex endovascular procedures. J VasC Surg 60: 742-748, 2014

23) Kirkwood ML, Arbique GM, Guild JB, Timaran C, Valentine RJ, Anderson JA: Radiation-induced skin 
injury after complex endovascular procedures. J Vasc Surg 60: 742-748, 2014

24) Valentin J: Avoidance of radiation injuries from medical interventional procedures. Ann ICRP 30: 7-67, 2000

25) Kondziolka D, Niranjan A, Lunsford LD, Flickinger JC: Radiobiology of radiosurgery. Prog Neurol Surg 20: $16-27,2007$

26) Choo DM, Shankar JJ: Onyx versus nBCA and coils in the treatment of intracranial dural arteriovenous fistulas. Interv Neuroradiol 22: 212-216, 2016
27) Rabinov JD, Yoo AJ, Ogilvy CS, Carter BS, Hirsch JA: ONYX versus n-BCA for embolization of cranial dural arteriovenous fistulas. J Neurointerv Surg 5: 306-310, 2013

Corresponding author: Tetsu Satow, MD, PhD

Department of Neurosurgery, National Cerebral and Cardiovascular Center, 6-1 Kishibeshinmachi, Suita, Osaka, Japan.

e-mail: tetsus@ncvc.go.jp 